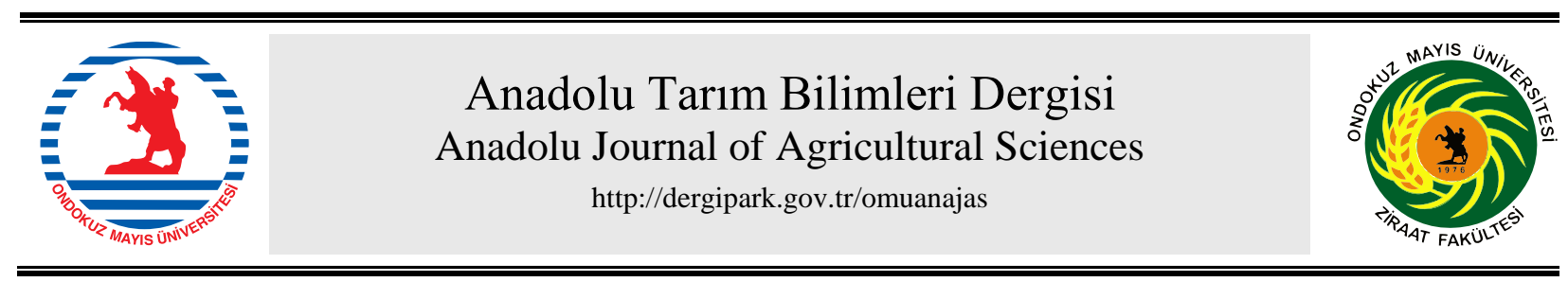

Araştırma/Research

Anadolu Tarım Bilim. Derg./Anadolu J Agr Sci, 36 (2021)

ISSN: 1308-8750 (Print) 1308-8769 (Online)

doi: 10.7161/omuanajas.669387

\title{
Morfolojik Ve Moleküler Yöntemlerle Çeltikte (Oryza sativa L.) Generatif Dönem Soğuk Stresinin Etkilerinin Belirlenmesi ๑Rasim Ünan ${ }^{\mathrm{a}^{*}}$, ๑Temel Gençtan ${ }^{\mathrm{b}}$
}

${ }^{a}$ Karadeniz Tarımsal Araştırma Enstitüsü, Samsun, Türkiye

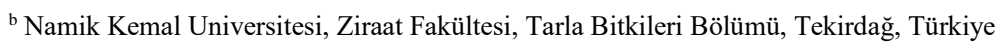

*Sorumlu yazar/corresponding author: rasimunan@hotmail.com

Geliş/Received 16/01/2020

Kabul/Accepted 03/12/2020

\begin{abstract}
ÖZET
Çeltik tropikal bir bitki olup soğuktan olumsuz yönde etkilenmektedir, bununla birlikte Türkiye gibi 1lıman iklim bölgelerinde tarımı yapılmaktadır. Bu çalışma bazı çeltik genotiplerinde generatif dönemde kontrollü şartlarda oluşturulan soğuk stresinin etkilerini belirlemek amacıyla yapılmıştır. Deneme 13 çeltik genotipi üzerinde Edirne Trakya Tarımsal Araştırma Enstitüsünde 2013, 2014 ve 2015 yıllarında yürütülmüştür. Generatif dönemdeki çeltikler bitki büyütme kabininde 8 gün boyunca $9{ }^{\circ} \mathrm{C}$ soğuk uygulaması yapılmış ve sera ortamına transfer edilerek olgunlaşma dönemi sonunda hasat edilmiştir. Deneme tesadüf parselleri deneme deseninde 3 tekerrürlü olarak yürütülmüştür. Hasatta sterilite ölçümü yapılarak genotipler generatif dönem soğuk stresi yönünden sınıflandırılmıştır. Sonuçta kontrol uygulamasında \% 11.3 sterilite ölçülürken, soğuk uygulamasında \% 30.8 sterilite ölçülmüştür. Soğuk stresi sterilite oranını \% 272.6 artırmıştır. Indika tipi çeltiklerin Japonika tipi çeltiklere göre daha hassas oldukları gözlenmiştir. Tunca, Hamzadere ve IR50 çeşitleri hassas olarak belirlenirken, Paşalı, Mevlütbey ve Halilbey çeşitleri toleranslı olarak belirlenmiştir. Ayrıca moleküler tekniklerle, üç, yedi ve dokuzuncu kromozom üzerinde bulunan üç farklı QTL (Kantitatif Özellik Lokusu) bölgesi taranarak generatif dönemde soğuk toleransı incelenmiştir. Moleküler sonuçlarla morfolojik sonuçların benzer olduğu tespit edilmiştir. Generatif dönemde soğuk stresi yaşanan bölgelerde seçilen çeşitlerin kullanılması tavsiye edilmektedir.
\end{abstract}

\section{Determination Of Cold Stress Effect At Reproductive Stage In Rice By Morphological And Molecular Methods ABSTRACT}

Rice is a tropical plant and does not have an inbuilt resistance to cold, however, in Turkey and elsewhere it is grown in temperate regions. Evaluation of cold tolerance under controlled temperature conditions may be performed. The aim of this study was to determine the effect of cold stress on rice genotypes at the booting stage. The experiment conducted on 13 rice genotype at Edirne Trakya Agricultural Research Institute in 2013, 2014 and 2015. The experiments were designed in a randomized plot with 3 replicates. Cold tolerance was evaluated on Booting stage by-holding them at $9^{\circ} \mathrm{C}$ for 8 days then rice transfered greenhouse until maturity time. Rice panicle harvested and genotyps classed in cold tolerance class according to sterility percentage at booting stage cold stress. Results revealed that cold stress increased the sterility $272.6 \%$. Sterility was measured $11.3 \%$ and $30.8 \%$ in control and cold stress application, respectively. The varieties which Tunca, Hamzadere and IR50 were found as susceptible. Pasalı Mevlutbey and Halilbey varieties were found as tolerant at booting stage. It was observed that indicated types where more susceptible to cold than Japonca types. Furthermore, it was aimed to determine cold stress at booting stages by molecular methods as inspecting three QTLs on 3, 7, 9 number genes, respectively. It was determined similar results between molecular and morphological cold tolerance results. It is recommended to grow up the selected rice varieties in the regions where cold stress occur during the booting stage.
Anahtar Sözcükler:

Çeltik

Generatif dönem

Soğuk stresi

Stretilite

Keywords:

Booting stage

Cold stress

Rice

Sterility

(c) OMU ANAJAS 2021 


\section{Giriş}

Çeltik, 7 milyarı aşkın dünya nüfusunun yarıdan fazlasının temel gıda maddesini oluşturmaktadır. Dünyanın bilinen en eski tahıl ürünlerinden birisidir. M.Ö. 6200 - 11500 yıllarında kültüre alındığını kanıtlayan genetik çalışmalar mevcuttur (Molina ve ark., 2011). Ana vatanı Çin olduğu tahmin edilen çeltik, Sri Lanka ve Hindistan gibi ülkeler aracığıyla dünyaya yayılmıştır. Güney Avrupa ve Kuzey Afrika'ya yayılan çeltik, Portekiz ve İspanya'dan Brezilya ve Orta Amerika'ya ulaşmıştır. Ülkemize girişi ise 500 yıl öncesine dayanmaktadır (Kün, 1985).

Ülkemizde sulanabilir alanlarda yetiştiriciliği yapılan çeltiğin en önemli problemlerinden biri de soğuk stresidir. Sıcak iklim bitkisi olan çeltikte; soğuk stresinin olumsuz etkileri çimlenme, fide gelişme, generatif dönem (sapa kalkma dönemi) ve olum dönemlerinde görülmektedir. Soğuk stresi çeltikte; çimlenme döneminde düşük çimlenme yüzdesi, çimlenmenin gecikmesi veya çimlenememe şeklinde ortaya çıkmaktadır. Fide gelişme döneminde soğuk stresi; fide gelişimin engellenmesi, yaprak renginin açılması, renksizleşmesi, kıvrılması şeklinde görülmekte generatif dönemde ise, polen oluşumunun engellenmesi ve salkım oluşumunun zarar görmesi şeklinde olmaktadır. Soğuk stresinin olum dönemindeki etkileri genellikle taneye besin maddesi taşınmasının engellenmesi, yaprakların klorofil kaybı ve erken yaşlanma (senesens) şeklinde görülebilmektedir (Chung, 1979).

Çeltikte soğuk zararının en önemli zararlarından biri, salkımın kın içinde olduğu ve sapın üst kısmındaki boğumun şişkin görüldüğü (generatif dönem, sapa kalkma, gebeleşme) döneminde görülmektedir. Bu dönemde özellikle gece saatlerindeki soğuklar, çeltik çiçeklerinde polen canlılığını azalması sonucu döllenmeyi aksatmaktadır. Bu durum, salkımda steril tane sayısının artmasına, doğal olarak da tane veriminde büyük düşüşlere neden olmaktadir.

Bu çalışmada; çeltik çeşit ve hatların soğuğa tolerans yönünden taranması ve generatif dönemdeki soğuk stresine tepkilerinin belirlenmesi amaçlanmıştır. Ayrıca, generatif dönemdeki laboratuvar testleri ve moleküler yöntemlerle soğuğa toleranslı olarak belirlenen genotiplerin, materyal olarak ıslah çalışmalarında kullanılması amaçlanmıştır.

Şekil 1. Çeltiğin fenolojik gelişme dönemleri

Figure 1. Rice growth stage scale

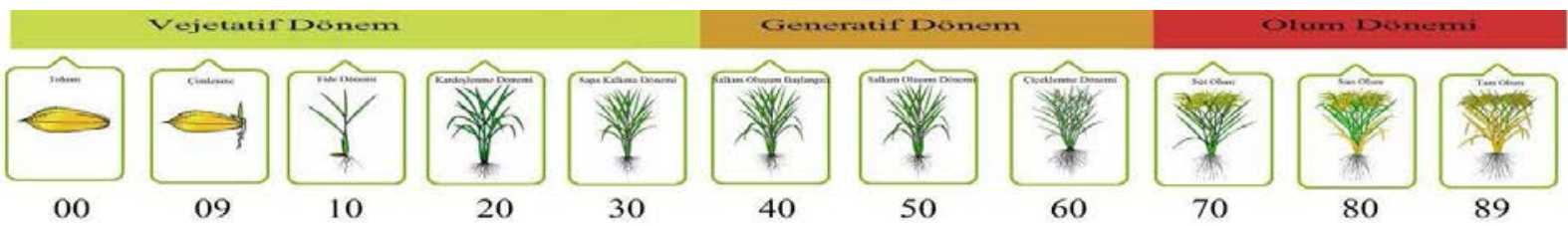

\section{Materyal ve Yöntem}

Çalışma ülkemizde yaygın olarak yetiştirilen 11 çeltik çeşidi ile kontrol olarak soğuğa hassas IR 50 çeşidi ile soğuğa toleranslı HSC 55 çeşidi olmak üzere Çizelge 1'de verilen 13 çeşit ile yürütülmüştür.

Çizege 1. Çalışmada yer alan çeltik çeşitleri

Table 1 . Variety names of materials

\begin{tabular}{cccc}
\hline No & Ad1 & No & Ad1 \\
\hline 1 & KIZILTAN & 8 & TUNCA \\
2 & PAŞALI & 9 & AROMATIK-1 \\
3 & TOSYAGÜNEŞI & 10 & HAMZADERE \\
4 & DURAĞAN & 11 & MEVLÜTBEY \\
5 & HALİLBEY & 12 & IR50 (hassas) \\
6 & EDİRNE & 13 & HSC55 (toleransli) \\
\hline
\end{tabular}

İncelenen genotiplerin generatif dönemde (Şekil 1) soğuğa toleranslarını belirlemek için Andaya ve Mackill (2003) yöntemi kullanılmıştır. Bu yöntemde; salkımın kın içinde şişmeye başladığı sapa kalkma (GS30) döneminde saksı içeresindeki çeltik 8 gün boyunca $9{ }^{\circ} \mathrm{C}$ soğuk etkisinde bırakılmış, hasatta steril taneler tespit edilmiştir. İncelenen genotipler aynı zaman dilimi içersinde generatif döneme (sapa kalkma) gelmedikleri için, düzenli gözlem yapılarak tüm genotiplere soğuk uygulamasının generatif dönemde yapılması sağlanmıştır. Soğuk uygulamasından sonra olum döneminde salkımlarda oluşan sterilite oranları saptanmıştır. Salkımda bulunan boş tanelerin toplam tane 
sayısına oranlanması ile \% sterilite oranı belirlenmiştir. Generatif dönemde soğuk uygulaması sonucu etkilenen çeşitler \% sterilite oranlarına göre gruplandırılmıştır. \% 0-25 sterilite oranına sahip olanlar "Toleranslı", \% 26-45 sterilite oranına sahip olanlar "Orta toleranslı" ve \% 45'den fazla sterilite oranına sahip olanlar "Hassas" olarak değerlendirilmiştir.

Çalışmada çeltikte soğuk stresine toleransı belirlemek için sapa kalkma dönemlerine ilişkin gen bölgelerini amplifiye edecek spesifik primerler (Suh ve ark. 2010) kullanılmıştır (Çizelge 2). Bu amaçla generatif dönemde 3, 7 ve 9. genlerde QTL bölgelerini tanımlayan 3 adet primer çifti kullanılmıştır.

Çizelge 2. Sapa kalkma dönemi primerler (Suh ve ark., 2010; Kim ve ark., 2014)

Table 2. Primers for booting stage in rice (Suh ve ark., 2010; Kim ve ark., 2014)

\begin{tabular}{|l|l|l|l|l|}
\hline Dönem & G & Primer & Nükleotid Dizimi (5'- 3') & $\begin{array}{l}\text { Bant } \\
\text { (Bp) }\end{array}$ \\
\hline $\begin{array}{l}\text { Sapa } \\
\text { Kalkma }\end{array}$ & 3 & RM231 & $\begin{array}{l}\text { F:ccagattatttcctgaggtc, } \\
\text { R:cacttgcatagttctgcattg }\end{array}$ & 186 \\
\hline $\begin{array}{l}\text { Sapa } \\
\text { Kalkma }\end{array}$ & 7 & $\begin{array}{l}\text { RM137 } \\
7\end{array}$ & $\begin{array}{l}\text { F:attagatacatcagcggggg, } \\
\text { R:gctgctgtacgatgtgatcc }\end{array}$ & 145 \\
\hline $\begin{array}{l}\text { Sapa } \\
\text { Kalkma }\end{array}$ & 9 & $\begin{array}{l}\text { RM245 } \\
45\end{array}$ & $\begin{array}{l}\text { F:acagcacagcacccggaagg, } \\
\text { R:cgagcaacaggaaggcgata } \\
\text { agc }\end{array}$ & 152 \\
\hline
\end{tabular}

\section{Bulgular ve Tartışma}

\subsection{Generatif dönem soğuk toleransı morfolojik bulgular:}

Generatif dönem soğuk toleransı yönünden çeltiğin en hassas olduğu dönemlerden biridir. Generatif dönem soğuk toleransı, çimlenme ve fide gelişim döneminden farklı olarak, oluşan soğuk şartların hemen ardındaki zaman diliminde değil salkımların hasat olgunluğuna geldiği dönemde tespit edilir. Generatif dönemde gerçekleşen soğuk stresi steriliteye neden olmaktadır. Bu nedenle salkımlardan ölçülen sterilite miktarları bu dönem için soğuk zararının bir göstergesi olarak kullanılmaktadır.

Generatif dönemde soğuk şartlar sterilite miktarını artırmak suretiyle tane verimini düşürmektedir. 2013, 2014 ve 2015 deneme yıllarında, yılların ve çeşitlerin generatif dönem soğuk uygulamasının sterilite oranı üzerine etkisine ilişkin varyans analizi sonuçları Çizelge 3 'te verilmiştir.

Çizelge 3 incelendiğinde, 2013, 2014 ve 2015 yılları birlikte değerlendirildiğinde ele alınan bütün parametrelerin ve Yıl $\times$ Uygulama interaksiyonu hariç diğer interaksiyonların sterilite oranı üzerine önemli etki yaptığı görülmektedir. Uygulama, çeşitler ile yıl $\times$ çeşit, uygulama $\times$ çeşit, yıl $\times$ uygulama $\times$ çeşit interaksiyonları istatistiki olarak 0.01 düzeyinde; yıllar 0.05 düzeyinde önemli bulunmuştur. Yıllar arasındaki fark önemli çıktığ için her yıl ayrı ayrı değerlendirilmiştir.

Çizelge 4'ün incelenmesinden; 2013 yılında generatif dönemde soğuk uygulaması \% 26.1 sterilite oluştururken, kontrol uygulaması \% 10.1 sterilite gerçekleştirmiştir. Sterilite oranının soğuk uygulamasından etkilendiği dikkati çekmektedir. Soğuk uygulaması normal sıcaklık değerlerine oranla üç kata yakın sterilite gerçekleştirmiştir. En yüksek sterilite oranı \% 37.2 ile IR50 çeşidinden, en düşük sterilite oranı ise \% 7.9 ile Kızıltan çeşidinden elde edildiği görülmektedir. Uygulama $\times$ çeşit interaksiyonu incelendiğinde soğuk uygulamasında Tunca çeşidi \% 50.1 ile en yüksek sterilite oranı, normal sıcaklıkta ise Kızıltan çeşidi \% 4.7 ile en düşük sterilite oranına sahip olmuştur.

Kontrol çeşitleri göz ardı edildiğinde soğuk uygulamasında Tunca çeşidi en yüksek sterilite oranı ile ilk sırada yer almış, Kızıltan çeşidi en düşük sterilite oranına sahip olmuştur. Kontrol uygulamasında Aromatik-1 çeşidi en yüksek sterilite oranı, Kızıltan çeşidi en düşük sterilite oranı göstermiştir. Özellikle Tunca çeşidi kontrol uygulamasına göre 42.4 puanlık fark oluşturmuştur. Aromatik-1, Paşalı ve Kızıltan ise soğuktan en az etkilenen çeşitler olmuştur.

Çizelge 5’in incelenmesinden; 2014 yllında generatif dönemde soğuk uygulaması \% 32.0 sterilite oluştururken, kontrol uygulaması \% 10.4 sterilite gerçekleştirmiştir. Sterilite oranının soğuk uygulamasından etkilendiği dikkati çekmektedir. Soğuk uygulaması normal sıcaklık değerlerine oranla üç kattan fazla sterilite gerçekleştirmiştir. En yüksek sterilite oranı \% 39.2 ile Tunca çeşidinden, en düşük sterilite oranı ise $\% 13.2$ ile Mevlütbey çeşidinden elde edildiği görülmektedir. Uygulama $\times$ çeşit interaksiyonu incelendiğinde soğuk uygulamasında Tunca çeşidi \% 52.6 ile en yüksek sterilite oranı, normal sıcaklıkta ise Kızıltan ve Edirne çeşidi \% 5.7 ile en düşük sterilite oranına sahip olmuştur. 
Çizelge 3. Çeltik çeşitlerinde sapa kalkma dönemi soğuk uygulamasının sterilite oranı üzerine varyans analizi Table 3. Variance analysis on the sterility varieties and cold application at booting stage in rice.

\begin{tabular}{ccrrr}
\hline Varyasyon & $\begin{array}{c}\text { Serbestlik } \\
\text { Derecesi }\end{array}$ & Kareler Toplamı & \multicolumn{2}{c}{ Kareler } \\
Ortalaması & \multicolumn{1}{c}{ Hesaplanan } \\
Kaynağı & 2 & 1351.47 & 675.74 & $8.66^{*}$ \\
Y1l & 6 & 874.22 & 145.70 & 1.87 \\
Tekerrür & 1 & 22128.80 & 22128.80 & $283.68^{* *}$ \\
Uygulama & 2 & 366.28 & 183.14 & 2.35 \\
Yıl x Uygulama & 6 & 468.04 & 78.01 & $68.23^{* *}$ \\
Hata 1 & 12 & 13968.70 & 1164.06 & $2.89^{* *}$ \\
Çeşit & 24 & 1182.46 & 49.27 & $32.99^{* *}$ \\
Y1l x Çeşit & 12 & 6753.15 & 562.76 & $2.90^{* *}$ \\
Uygulama x Çeşit & 24 & 1186.59 & 49.44 & \\
Y1l x Uygulama x Çeşit & 144 & 2456.70 & 17.06 & \\
Hata 2 & 233 & 50736.40 & 217.75 & \\
Genel & & & & \\
\hline
\end{tabular}

* = \% 5 düzeyinde önemli ** = \% 1 düzeyinde önemli; CV $(\%)=19.1$

Çizelge 4. Çeşitler ve sapa kalkma dönemi soğuk uygulamasının 2013 yılındaki sterilite oranı üzerine etkisi (\%) Table 4. The effect of cold stress between booting stage and varieties on sterility rate in 2013 (\%)

\begin{tabular}{|c|c|c|c|}
\hline \multirow[b]{2}{*}{ Cesitler } & \multicolumn{2}{|c|}{ Uygulamalar } & \multirow[b]{2}{*}{ Ortalama } \\
\hline & Kontrol Uygulaması & Soğuk Uygulaması & \\
\hline 1- Kiziltan & $4.7 \mathrm{k}^{*}$ & $11.2 \mathrm{fi}$ & $7.9 \mathrm{~h}$ \\
\hline 2- Paşali & $10.7 \mathrm{~g}_{1}$ & $13.4 \mathrm{eg}$ & $12.0 \mathrm{~g}$ \\
\hline 3- Tosyagüneşi & $10.0 \mathrm{gj}$ & $20.8 \mathrm{~d}$ & $15.4 \mathrm{ef}$ \\
\hline 4- Durağan & $8.7 \mathrm{hk}$ & $29.4 \mathrm{c}$ & $19.0 \mathrm{~d}$ \\
\hline 5- Halilbey & $8.0 \mathrm{hk}$ & 16.4 de & $12.2 \mathrm{fg}$ \\
\hline 6- Edirne & $7.3 \mathrm{kk}$ & $32.5 \mathrm{c}$ & $19.9 \mathrm{~d}$ \\
\hline 7- Osmancık-97 & $6.7 \mathrm{1k}$ & $30.0 \mathrm{c}$ & 18.3 de \\
\hline 8- Tunca & $7.7 \mathrm{1k}$ & $50.1 \mathrm{a}$ & $28.9 \mathrm{~b}$ \\
\hline 9- Aromatik-1 & 15.4 ef & 15.7 ef & $15.5 \mathrm{e}$ \\
\hline 10- Hamzadere & $6.0 \mathrm{jk}$ & $44.7 \mathrm{~b}$ & $25.3 \mathrm{c}$ \\
\hline 11- Mevlütbey & $7.3 \mathrm{lk}$ & $17.0 \mathrm{de}$ & $12.2 \mathrm{fg}$ \\
\hline 12- IR50 (Hassas Kon.) & $28.7 \mathrm{c}$ & $45.7 \mathrm{ab}$ & $37.2 \mathrm{a}$ \\
\hline 13- HSC55 (Tol. Kon.) & $10.3 \mathrm{gj}$ & $12.4 \mathrm{eh}$ & $11.3 \mathrm{~g}$ \\
\hline Ortalama & $10.1 \mathrm{~b}$ & $26.1 \mathrm{a}$ & \\
\hline EKÖF $(\mathrm{P}<0.05)$ & \multicolumn{3}{|c|}{ Uygulama $=1.38$, Uygulama $\times$ Cessit $=4.64$, Cessit $=3.28$} \\
\hline CV (\%) & \multicolumn{3}{|c|}{15.6} \\
\hline
\end{tabular}

Kontrol çeşitleri göz ardı edildiğinde soğuk uygulamasında Tunca çeşidi en yüksek sterilite oranı ile ilk sırada yer almış, Mevlütbey çeşidi en düşük sterilite oranına sahip olmuştur. Kontrol uygulamasında Tunca çeşidi en yüksek sterilite oranı, Kızıltan çeşidi en düşük sterilite oranı göstermiştir. Özellikle Hamzadere, Edirne ve Tunca çeşitleri kontrol uygulamasına göre 38.8, 32.4 ve 27 puanlık fark oluşturmuştur. Aromatik-1, Mevlütbey ve Halilbey çeşitleri ise soğuktan en az etkilenen çeşitler olmuştur.

Çizelge 6'in incelenmesinden; 2015 yılında generatif dönemde soğuk uygulaması \% 34.4 sterilite oluştururken, kontrol uygulaması \% 13.6 sterilite gerçekleştirmiştir. Sterilite oranının soğuk uygulamasından etkilendiği dikkati çekmektedir. Soğuk uygulaması normal sıcaklık değerlerine oranla üç kata yakın sterilite gerçekleştirmiştir. En yüksek sterilite oranı \% 48.1 ile IR50 çeşidinden, en düşük sterilite oranı ise $\% 16.1$ ile Halilbey çeşidinden elde edildiği görülmektedir. Uygulama x çeşit interaksiyonu incelendiğinde soğuk uygulamasında IR50 çeşidi \% 62.1 ile en yüksek sterilite oranı, normal sıcaklıkta ise HSC55 çeşidi \% 7.7 ile en düşük sterilite oranına sahip olmuştur. 
Çizelge 5. Çeşitler ve generatif dönem soğuk uygulamasının 2014 yılındaki sterilite oranı üzerine etkisi (\%)

Table 5. The effect of cold stress between booting stage and varieties on sterility rate in 2014 (\%)

\begin{tabular}{|c|c|c|c|}
\hline & \multicolumn{3}{|c|}{ Uygulamalar } \\
\hline Çeşitler & Kontrol Uygulamas1 & Soğuk Uygulaması & Ortalama \\
\hline 1- Kiziltan & $5.7 \mathrm{~h} *$ & 24.4 ef & $15.1 \mathrm{fg}$ \\
\hline 2- Paşalı & $6.0 \mathrm{~h}$ & $20.6 \mathrm{fg}$ & $13.3 \mathrm{~g}$ \\
\hline 3- Tosyagüneşi & $6.3 \mathrm{~h}$ & $23.1 \mathrm{eg}$ & $14.7 \mathrm{fg}$ \\
\hline 4- Durağan & $9.0 \mathrm{~h}$ & $34.6 \mathrm{~cd}$ & $21.8 \mathrm{de}$ \\
\hline 5- Halilbey & $9.3 \mathrm{~h}$ & $20.1 \mathrm{fg}$ & $14.7 \mathrm{fg}$ \\
\hline 6- Edirne & $5.7 \mathrm{~h}$ & $38.1 \mathrm{c}$ & 21.9 de \\
\hline 7- Osmancık-97 & $8.7 \mathrm{~h}$ & $33.7 \mathrm{~cd}$ & 21.2 de \\
\hline 8- Tunca & 25.7 ef & $52.6 \mathrm{a}$ & $39.2 \mathrm{a}$ \\
\hline 9- Aromatik-1 & $23.1 \mathrm{ef}$ & 24.7 ef & $23.9 \mathrm{~cd}$ \\
\hline 10- Hamzadere & $7.3 \mathrm{~h}$ & $46.1 \mathrm{~b}$ & $26.7 \mathrm{c}$ \\
\hline 11- Mevlütbey & $9.7 \mathrm{~h}$ & $16.7 \mathrm{~g}$ & $13.2 \mathrm{~g}$ \\
\hline 12- IR50 (Hassas Kon.) & $9.7 \mathrm{~h}$ & $54.1 \mathrm{a}$ & $31.9 \mathrm{~b}$ \\
\hline 13- HSC55 (Tol. Kon.) & $7.0 \mathrm{k}$ & 28.8 de & 17.9 ef \\
\hline Ortalama & $10.4 \mathrm{~b}$ & $32.0 \mathrm{a}$ & \\
\hline EKÖF $(\mathrm{P}<0.05)$ & & Uygulama $=12.69$, Uygulam & 3, Çeşit $=4.54$ \\
\hline CV (\%) & & 18 & \\
\hline
\end{tabular}

Çizelge 6. Çeşitler ve generatif dönem soğuk uygulamasının 2015 yılında sterilite oranı üzerine etkisi (\%) Table 6. The effect of cold stress between booting stage and varieties on sterility rate in 2015 (\%)

\begin{tabular}{|c|c|c|c|}
\hline Çeşitler & Kontrol Uygulamas1 & Soğuk Uygulaması & Ortalama \\
\hline 1- Kiziltan & $8.7 \mathrm{k}^{*}$ & $27.6 \mathrm{eg}$ & $18.1 \mathrm{~d}$ \\
\hline 2- Paşalı & $12.3 \mathrm{jk}$ & $22.8 \mathrm{~g} 1$ & $17.6 \mathrm{~d}$ \\
\hline 3- Tosyagüneşi & $8.0 \mathrm{k}$ & $26.0 \mathrm{fh}$ & $17.0 \mathrm{~d}$ \\
\hline 4- Durağan & $15.3 \mathrm{ij}$ & 35.0 de & 25.2 c \\
\hline 5- Halilbey & $9.0 \mathrm{k}$ & $23.1 \mathrm{~g} 1$ & $16.1 \mathrm{~d}$ \\
\hline 6- Edirne & $9.3 \mathrm{k}$ & $40.3 \mathrm{~cd}$ & $24.8 \mathrm{c}$ \\
\hline 7- Osmancık-97 & $9.2 \mathrm{k}$ & $34.4 \mathrm{df}$ & $21.8 \mathrm{~d}$ \\
\hline 8- Tunca & $18.7 \mathrm{hj}$ & $50.3 \mathrm{~b}$ & 34.5 b \\
\hline 9- Aromatik-1 & $25.3 \mathrm{gh}$ & $28.2 \mathrm{eg}$ & $26.8 \mathrm{c}$ \\
\hline 10- Hamzadere & $8.0 \mathrm{k}$ & $45.6 \mathrm{bc}$ & $26.8 \mathrm{c}$ \\
\hline 11- Mevlütbey & $11.3 \mathrm{jk}$ & $23.7 \mathrm{~g} 1$ & $17.5 \mathrm{~d}$ \\
\hline 12- IR50 (Hassas Kon.) & $34.0 \mathrm{df}$ & $62.1 \mathrm{a}$ & $48.1 \mathrm{a}$ \\
\hline 13- HSC55 (Tol. Kon.) & $7.7 \mathrm{k}$ & $27.5 \mathrm{eg}$ & $17.6 \mathrm{~d}$ \\
\hline Ortalama & $13.6 \mathrm{~b}$ & $34.4 \mathrm{~b}$ & \\
\hline EKÖF (P<0.05) & \multicolumn{3}{|c|}{ Uygulama $=7.68$, Uygulama $x$ Çeşit $=8.66$, Çeşit $=6.13$} \\
\hline CV (\%) & \multicolumn{3}{|c|}{19.2} \\
\hline
\end{tabular}

* Aynı harfi taşıyan ortalamalar arasında \% 5 düzeyinde önemli fark bulunmamaktadır

Kontrol çeşitleri göz ardı edildiğinde soğuk uygulamasında Tunca çeşidi en yüksek sterilite oranına, Paşalı çeşidi ise en düşük sterilite oranına sahip olmuştur. Kontrol uygulamasında Aromatik1 çeşidi en yüksek sterilite oranı, Hamzadere ve Tosyagüneşi çeşidi en düşük sterilite oranı göstermiştir. Özellikle Hamzadere, Tunca ve Edirne çeşitleri kontrol uygulamasına göre 37.6, 31.6 ve 31.0 puanlık yüksek fark oluşturmuştur. Aromatik-1, Paşalı ve Mevlütbey çeşitleri ise soğuktan en az etkilenen çeşitler olmuştur.

Çizelge 7 incelendiğinde çeşitlerin toleranslı, orta toleranslı ve hassas olarak üç gruba ayrıldı̆̆ 1 görülmektedir. Üç yıllık çalışma ortalamasına göre soğuk şartlarda \% 45'den fazla sterilite gösteren çeşitler hassas, \% 25-45 arası sterilite gösterenler orta toleranslı ve \% 25 'den az olanlar toleranslı 
olarak değerlendirilmiştir. Kızıltan, Paşalı, Halilbey, Mevlütbey ve HSC55 çeşitleri toleranslı bulunurken, Tunca Hamzadere ve IR50 çeşitleri hassas olarak sınıflandırılmıştır.

Çizelge 7. Generatif dönem soğuk toleransına göre çeşitlerin sınıflandırılması

Table 7. Categorization of varieties according to cold tolerance at booting stage in rice

\begin{tabular}{ccc}
\hline Toleranslı & Orta Toleranslı & Hassas \\
\hline Kızıltan & Edirne & Tunca \\
Paşalı & Durağan & Hamzadere \\
Halilbey & Osmancık-97 & IR50 \\
Mevlütbey & Tosyagüneşi & \\
HSC55 & Aromatik-1 & \\
\hline
\end{tabular}

Üç yıllık çalışma sonucunda elde ettiğimiz sonuçlara göre sterilite oranları normal koşullarda \% 4.7-34.0 arasında gerçekleşirken, soğuk uygulamasında \% 11.2 - 62.1 arasında gerçekleşmiştir. 5 adet çeşit toleransl1, 5 adet çeşit orta toleranslı ve 3 çeşit hassas olarak belirlenmiştir.

Çok sayıda araştırıcı yaptıkları çalışmalarında, çeltikte soğuk hava koşullarının salkımdaki fertiliteyi azaltıp, sterilite oranını artırdığını açıklamaktadır (Sürek, 2002; Khalif ve ark., 2007; Zenna ve ark., 2014). Araştırıcılar soğuk stresinin ekim zamanı ile bağlı olarak yıllara göre değişebildiğini ( Şavşatlı ve ark., 2008) ve oluşan tane sayısının çeşitlere bağlı olarak değiştiğini (Şavşatlı ve ark., 2006) vurgulamaktadır.

Araştırmamızdan elde ettiğimiz sonuçlar; düşük sıcaklık derecelerine tabi tutulan anterlerin zarar gördüğünü, steril mikrosporların arttı̆̆ını, salkım sretilitesinin arttığını ve verimin azaldığını bildiren Satake (1989) araştırma sonuçlarıyla; bütün gelişme dönemlerinde soğuk uygulamalarından indica tiplerin japonica tiplere oranla daha çok etkilendiğini, fakat sapa kalkma ve çiçeklenme döneminde indica tiplerin ve onların F1'lerinin daha toleranslı olduğunu bildiren Glaszmann ve ark., (1990) yayınıyla benzemektedir.

Soğuk uygulamasının salkımda tane sayısını azalttığını, salkım sterilitesini \% 90'a kadar artırdığını ve gelişme dönemleri karşılaş̧ırıldığında sapa kalkma döneminin çiçeklenme başlangıcı dönemine göre daha önemli olduğunu bildiren araştırmacılar Jacobs ve Pearson (1999) çalışma sonuçlarıyla; soğuk uygulamasıyla sterilitenin \%70'in üzerine çıktığını bildiren Li ve ark., (2014) sonuçlarıyla benzerlik göstermektedir.

Ayrıca, soğuk uygulamasında sterilite değerlerinin en az HSC55 çeşidinde \% 24.1, en fazla YRL 39 çeşidinde \% 95.8 olarak bulan ve soğuk uygulamasında sterilite değerlerinin \% 20.0-92.5 gerçekleştiğini belirten Bodapati ve ark., (2005) sonuçlarıyla; generatif dönem soğuk uygulaması sonucunda salkım sterilitesinin \% 27.9- 96.9 arasında gerçekleştiğini bildiren araştırmacılar Mori ve ark., (2011) yayınıyla, normal sıcaklıkta salkım sterilite oranları \%2.3-9.8 arasında gerçekleşirken, soğuk uygulamasında \%29.6-61.2 arasında gerçekleştiğini bildiren Zhou ve ark., (2012) bulgularıyla, kontrollü koşullarda soğuk uygulanan çeltiklerde \%72.9, aynı çeşitlerle tarla koşullarında \% 24.0 sterilite oranı bulan araştırmacılar Ghadirnezhad ve Fallah (2014) makelesiyle; sterilite oranlarının soğuk uygulamasında \% 35-100 arasında, normal koşullarda \% 6-44 arasında gerçekleştiğini bildiren Zenna ve ark., (2014) araştırma sonuçlarıyla bu çalışmadan elde edilen sonuçlar benzerlik göstermektedir.

\subsection{Generatif dönem soğuk toleransı moleküler bulgular}

Generatif dönemde 3, 7 ve 9. Kromozomlar üzerinde bulunan 186 bp, 145 bp ve 152 bp bandındaki 3 QTL taranmıştır. Bu üç QTL bölgesinden en az birine sahip olan çeşitler dayanıklı olarak tanımlanmaktadır. Üzerinde çalışılan çeşitlerin 46 tanesi toleranslı bulunurken 2 tanesi hassas olarak tespit edilmiştir.

3. kromozom üzerinde bulunan 186 bp QTL bölgesi incelendiğinde 16 nolu Aromatik-1 çeşidi ve 44 nolu IR50 (hassas kontrol) çeşidi hassas olarak belirlenmiştir. 45 nolu HSC55 (toleranslı kontrol) çeşidi ve diğer 45 çeşit belirtilen bölgede bant oluşumu gösterdiğinden toleranslı olarak belirlenmiştir (Şekil 2). 


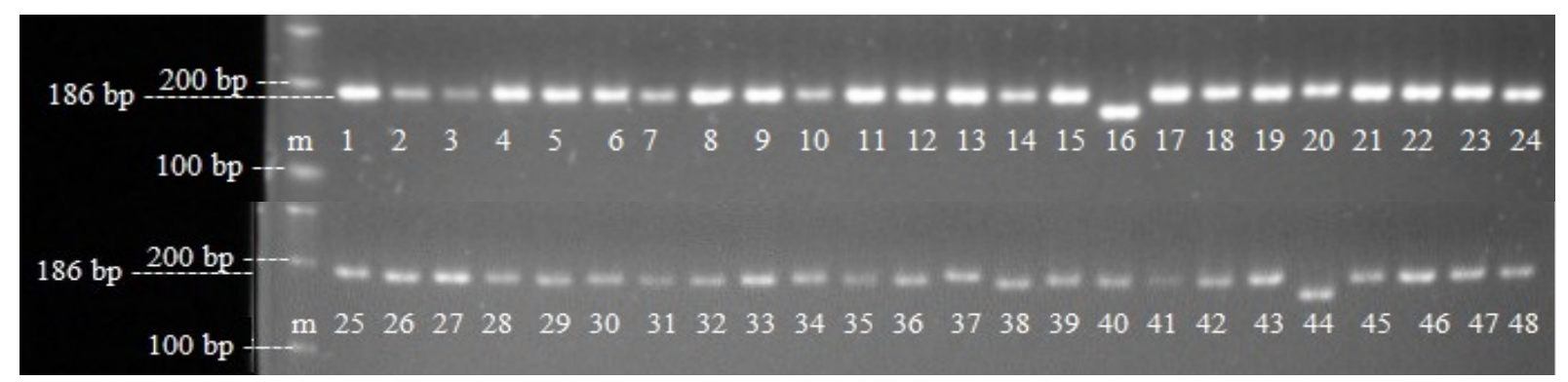

Şekil 2. Generatif dönem soğuk toleransı belirlemek için RM231 primerleri kullanılarak elde edilen ve 3 nolu kromozomda bulunan 186 bp QTL bölgesi bant görünümü (44: hassas kontrol, 45: toleranslı kontrol)

Figure 2. RM231 marker band pattern 186 bp QTL for the booting stage cold tolerance on chromozome 3 in rice (44: Susceptible ckeck, 45: Tolerant check).

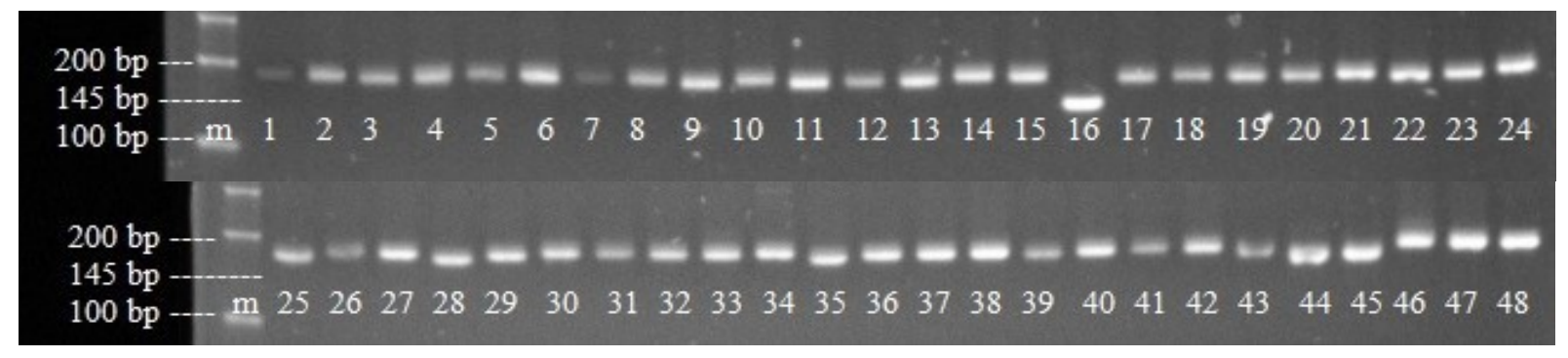

Şekil 3. Generatif dönem soğuk toleransı belirlemek için RM1377 primerleri kullanılarak elde edilen ve 7 nolu kromozomda bulunan 145 bp QTL bölgesi bant görünümü. 44: hassas kontrol, 45: toleransli kontrol. Figure 3. RM1377 marker band pattern 145 bp QTL for the booting stage cold tolerance on chromozome 7 in rice (44: Susceptible ckeck, 45: Tolerant check).

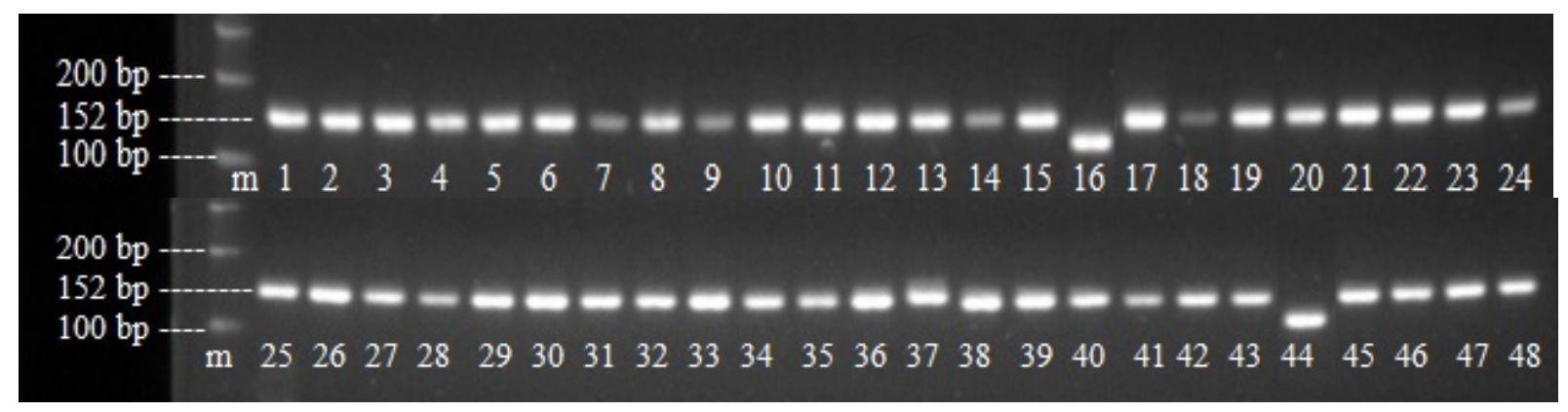

Şekil 4. Generatif dönem soğuk toleransı belirlemek için RM24545 primerleri kullanılarak elde edilen ve 9 nolu kromozomda bulunan 152 bp QTL bölgesi bant görünümü. 44: hassas kontrol, 45: toleranslı kontrol.

Figure 4. RM24545 marker band pattern 152 bp QTL for the booting stage cold tolerance on chromozome 9 in rice (44: Susceptible ckeck, 45: Tolerant check).

7. kromozom üzerinde bulunan 145 bp QTL bölgesi incelendiğinde sadece 16 nolu Aromatik-1 çeşidi bant oluşumu göstermiştir. Diğer çeşitlerin hiçbiri bant oluşumu göstermemiştir. 7. kromozom için belirtilen QTL bölgesi bu çalışma için iyi bir ayrım yapmamaktadır (Şekil 3).

9. kromozom üzerinde bulunan 152 bp QTL bölgesi incelendiğinde 16 nolu Aromatik-1 çeşidi ve 44 nolu IR50 (hassas kontrol) çeşidi hassas olarak belirlenmiştir. 45 nolu HSC55 (toleranslı kontrol) çeşidi ve diğer 45 çeşit belirtilen bölgede bant oluşumu gösterdiğinden toleranslı olarak belirlenmiştir (Şekil 4).

3, 7 ve 9 nolu kromozomlar bir arada değerlendirildiğine 16 nolu Aromatik-1 çeşidi ve 44 nolu IR50 (hassas kontrol) çeşidi her 3 ve 9 nolu kromozomlar üzeride bulunduğu belirlenmiş QTL bölgeleri için kullanılan primerlerle bant oluşturmamış ve moleküler çalışmada hassas olarak tespit edilmiştir. 45 nolu HSC55 (toleranslı kontrol) çeşidi ile birlikte toplam 46 çeşit 3 ve 9 nolu kromozomlarda belirtilen QTL bölgeleri için kullanılan primerler ile bant oluşumu gerçekleştirmiş ve toleranslı olarak değerlendirilmiştir. 7 kromozom için kullanılan 
primer ile sadece 16 nolu Aromatik-1 çeşidi bant oluşturmuş ancak diğer iki primer çifti ile uyumlu sonuç vermemiştir.

Çeltikte generatif dönem soğuk toleransı moleküler yöntemlerle değerlendirildiğinde 16 nolu Aromatik-1 çeşidi ve 44 nolu IR50 (hassas kontrol) çeşidi soğuğa hassas olarak belirlenmiş, 45 nolu HSC55 (toleranslı kontrol) çeşidi ve diğer 45 çeşit toleranslı olarak değerlendirilmiştir. Moleküler çalışma sonuçları Suh ve ark., 2010; Kim ve ark., 2014 araştırma sonuçlarıyla uyum içeresindedir.
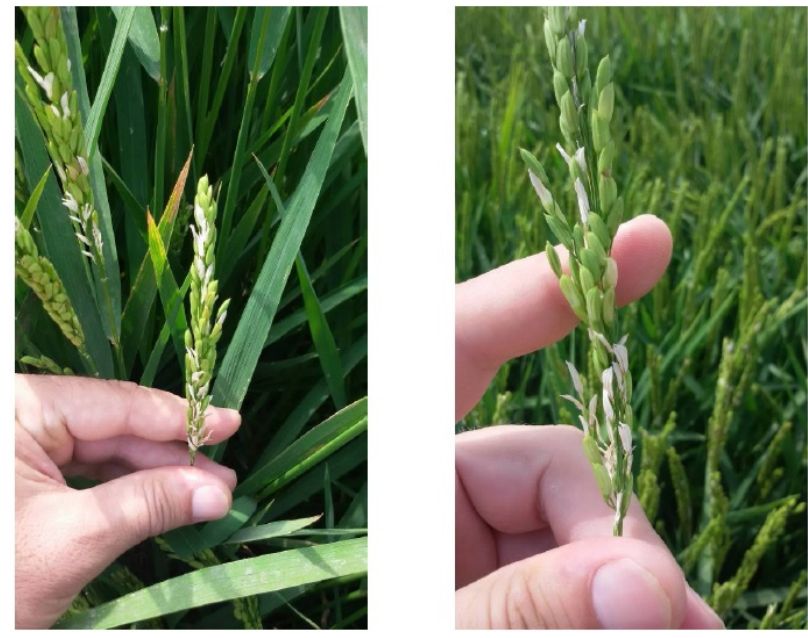

Şekil 5. Generatif dönem soğuk zararı sonucu oluşan steril taneler Figure 5. Sterile kernels caused by cold damage at the booting stage

\section{Sonuç}

Çeltikte generatif dönem, sapa kalkma dönemi olarak da adlandırılan salkımın kın içinde gelişmeye başladığ dönem, soğuk stresinin sterilite üzerinde en etkili olduğu dönemlerden biridir. Sapa kalkma dönemi soğuk stresi sonrasında steril taneler oluşmaktadır (Şekil 5). İncelenen 13 çeltik çeşidinin generatif dönemde soğuğa toleranslarını belirlemek amacıyla, bitkilere 8 gün boyunca $9{ }^{\circ} \mathrm{C}$ soğuk uygulanmış, daha sonra seraya alınarak olum dönemleri tamamlanmış ve hasatta sterilite oranları saptanmıştır.

13 çeltik çeşidinin üç farklı ekim zamanında 2013, 2014 ve 2015 yıllarında yürütülen tarla denemelerinde sterilite oranları \%4.7-34.0 arasında bulunmasına karşın, soğuk uygulamasında çeşitlerin sterilite oraları \%11.2-62.1 gibi çok yüksek düzeylere çıkmıştır.

Sonuçta kontrol uygulamasında ortalama \%11.3 sterilite ölçülürken, soğuk uygulamasında \%30.8 sterilite ölçülmüştür. Soğuk stresi sterilite oranını üç kata kadar yüzde ile ifade edildiğinde \%272.6 oranında artırmıştır. Soğuk uygulaması sonucunda; \%25'den az sterilite gösteren çeşitler "Toleranslı", \%25-45 arası sterilite gösteren çeşitler "Orta toleranslı" ve \%45'den fazla sterilite gösteren çeşitler "Hassas" olarak değerlendirilmiştir.

Buna göre generatif dönemde soğuğa karşı; Kızıltan, Paşalı, Halilbey, Mevlütbey ve HSC55 çeşidi toleransl1; Edirne, Durağan, Osmancık-97, Tosyagüneşi ve Aromatik-1 toleransl1; Tunca Hamzadere ve IR50 çeșitleri hassas olarak belirlenmiştir. Generatif dönemde 3, 7 ve 9. kromozomlar üzerinde bulunan 186 bp, 145 bp ve 152 bp bandındaki 3 QTL bölgesinin taranması ile incelenen çeşitlerin 46 tanesi toleranslı 2 tanesi hassas olarak belirlenmiş, orta toleranslı olarak bir gruplama yapılamamıştır. İncelenen çeşitlerden IR50 ve Aromatik-1 hassas olarak saptanmıştır.

\section{Teșekkür}

$\mathrm{Bu}$ çalışma TAGEM tarafından desteklenmiştir (TAGEM/TA/03/03/06/00), Namık Kemal Üniversitesinde tamamlanan doktora tezinin bir bölümünü içermektedir. 


\section{Kaynaklar}

Andaya, V.C., Mackill, D.J., 2003. QTLs conferring cold tolerance at the booting stage of rice using recombinant inbred lines from a japonica 9 indica cross. Theor Appl Genet 106:1084-1090

Bodapati, N., Gunawardena, T., Fukai, S., 2005. Increasing Cold Tolerance in Rice by selecting for high polyamine and gibberellic acid content. RIRDC Publication No 05/090. ISBN 1741511534 ISSN 1440-6845

Chung, G.S., 1979. The Rice Cold Tolerance Program in Korea. Report Of A Rice Cold Tolerance Workshop. IRRI Publications Manila, Philippines.

Ghadirnezhad, R., Fallah, A., 2014. Temperature Effect on Yield and Yield Components of Different Rice Cultivars in Flowering Stage. Hindawi Publishing Corporation International Journal of Agronomy, Article ID 846707, 4 pages.

Glaszmann, J.C., Kaw, R.N., Khush, G.S., 1990. Genetic divergence among cold tolerant rices (Oryza sativa L.). Euphytica 45: 95-104.

Jacobs BC, Pearson CJ (1999). Growth, development and yield of rice in response to cold temperature. J. Agron. Crop Sci.-Z. Acker Pflanzenbau 182(2): 79-88.

Khalif, A.A., Wahab, A.A.E., El-Ekhtyar, A.M., Zaed, B.A., 2007. Response of some hybrid rice varieties to irrigation intervals under different dates of sowing. African Crop Science Conference Proceedings. 8:67-74.

Kim, S.M., Suh, J.P., Lee, C.K., Lee, J.H., Kim, Y.G., Jena, K.K., 2014. QTL mapping and development of candidate gene-derived DNA markers associated with seedling cold tolerance in rice (Oryza sativa L.). Mol Genet Genomics 289:333-343

Kün, E., 1985. Sıcak iklim tahılları. Ankara Üniversitesi, Ziraat Fakültesi Yay.:953, Ders Kitabı: 275 Ankara Üniversitesi. Basımevi, Ankara.

Li, S.C., Zeng, Y.W., Shen, S.Q., Pu, X.Y., 2004. Cold Tolerance of Core Collection at Booting Stage Associated with Eco-geographic Distribution in Yunnan Rice Landrace (Oryza sativa), China. Rice Science. 11(5-6): 261268 .

Molina, J., Sikora, M., Garud, N., Flowers, J.M., Rubinstein, S., Reynolds, A., Huang, P., Jackson, S., Schaal, B.A., Bustamante, C.D., Boyko, A.R., Purugganan, M.D., 2011. Molecular evidence for a single evolutionary origin of domesticated rice. PNAS 108 (20): 8351-8356. Doi: 10.1073/pnas.1104686108.

Mori, M., Onishi, K., Tokizono, Y., Shinada, H., Yoshimura, T., Numao, Y., Miura, H., Sato, T. 2011. Detection of a novel quantitative trait locus for cold tolerance at the booting stage derived from a tropical japónica rice variety Silewah. Breeding Science 61: 61-68.

Satake, T., 1989. Male sterility caused by cooling treatment at the young microspore stage in rice plants. XXIX. The mechanism of enhancement in cool tolerance by raising water temperature before the critical stage. Jpn J Crop Sci., 58: 240-245

Şavşatli, Y., Köycü, C., Gülümser, A. 2006. Fideleme ve Serpme Ekim Yöntemlerinin Bazi Çeltik Çeşitlerinde Verim Ve Verim Unsurlarina Etkileri. Anadolu Tarım Bilimleri Dergisi. 21(1): 6-13

Şavşatlı, Y., Gülümser, A., Sezer, İ., 2008. Samsun Ekolojik Şartlarında Yetiştirilen Çeltik Genotiplerinin Verim Ve Verim Unsurları Bakımından Karşılaştırılması. OMÜ Zir. Fak. Dergisi 23(1): 7-16.

Suh, P., Jeung, J.U., Lee, J.I., Choi, Y.H., Yea, Y.D., Virk, P.S., Mackill, D.J., Jena, K.K., 2010. Identification and analysis of QTLs controlling cold tolerance at the reproductive stage and validation of effective QTLs in coldtolerant genotypes of rice (Oryza sativa L.). Theor Appl Genet 120: 985-995 Doi 10.1007/s00122-009-1226-8.

Sürek, H., 2002. Çeltik tarımı kitabı. Hasad yayıncılık, İstanbul.

Zenna, N., Ndomondo, M., Kwayu, R., Kumashiro, T. 2014. Phenotypic Evaluation of Rice for Reproductive Stage Cold Tolerance. 4th International Rice Congress \& 5th Temperate Rice Conference Oct 28-Nov 1, 2014 Bangkok-Thailand.

Zhou, L., Zeng, Y., Hu, G., Pan, Y., Yang, S., You, A., Zhang, H., Li, J., Li, Z., 2012. Characterization and identification of cold tolerant near-isogenic lines in rice. Breeding Science 62: 196-201 doi:10.1270/jsbbs.62.196 